\title{
SPARING OF SHORT-TERM MEMORY IN AN AMNESIC PATIENT: IMPLICATIONS FOR STRENGTH THEORY OF MEMORY*
}

\author{
WAYNE A. WICKELGREN \\ Massachusetts Institute of Technology, Cambridge, \\ Massachusetts 02139, U.S.A.
}

(Received 13 September 1967)

\begin{abstract}
Alsstract-Short-term recognition memory for single-digit numbers, three-digit numbers, and the pitch of pure tones was studied in a subject (H.M.) who appears to possess normal shortterm memory, but to be almost completely lacking in the ability to form new long-term memory traces. The primary purpose was to test the short-term memory component of a dualtrace strength theory developed for normal subjects. To a first approximation, H.M.'s tracestrength decay curves are exponential, as postulated by strength theory for short-term memory. Furthermore, the rate of decay of this trace for H.M. is well within the range of normal subjects. These findings agree with previous findings on H.M. in support of a dual-trace theory of memory. More particularly, the present findings support the strength theory of memory proposed by WICKELGREN and NORMAN [15].
\end{abstract}

AS A CONSEQUENCE of bilateral removal of the mesial parts of the temporal lobes, H.M. has an almost complete inability to form new long-term memory traces for both verbal and non-verbal stimuli. What is perhaps most remarkable about H.M.'s deficit is its purity. On the basis of present evidence, it appears that H.M. has no obvious personality change, no deficit in performance tests that involve only previously acquired knowledge (such as a standard intelligence test), very little remaining retrograde amnesia, no deficit in long-term motor-skill learning, and no deficit in immediate memory span. Naturally, it is still possible that some more sophisticated test would show a deficit in one of these areas where previous tests have not, but there is considerable support for the assertion that H.M.'s primary deficit is in the formation of new long-term memory traces for stimuli. For a complete review of findings concerning H.M., see MILNER [5] and other papers in this issue.

H.M.'s apparently normal short-term memory, accompanied by virtually complete inability to form new long-term memory traces, provides a remarkable opportunity to test theories of short-term memory under conditions where one can be quite sure that little or no long-term memory is contaminating the results. The present paper tests whether H.M.'s performance in certain verbal and non-verbal short-term recognition memory tasks can be adequately described by the short-term memory component of a particular theory, namely, strength theory $[12,14,15]$.

The major assumptions of strength theory as applied to short-term recognition memory are as follows: (a) The short-term memory trace for an item can be described by a single

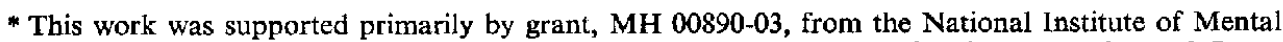
Health, U.S. Public Health Service. Further aid was received from a National Aeronautics and Space Administration grant NsG 496, to Hans-Lukas Teuber. 
real-valued random variable (the "strength" of the item); (b) The mean of this random variable is incremented by presentation of the item and decays (exponentially) as a function of the duration of the filled (rehearsal-preventing) delay interpolated between presentation and the test of the item; (c) The decision rule used to determine whether or not the test item has been presented previously is the criterion decision rule of signal-detection theory (decide "yes", if and only if the strength of the test item in memory exceeds a criterion).

There are two subsidiary assumptions which also seem to be approximately valid for normal subjects, namely, that the noise in trace strength is normally distributed, and that the variance is independent of the mean. These subsidiary assumptions simplify computation, but are in no sense crucial for strength theory.

Strength theory has previously provided a rather good description of the performance of normal subjects in the same short-term memory tasks to be used in the present study with H.M., namely, recognition memory for three-digit numbers [15] and the pitch of pure tones [14]. However, in the latter case, but not the former case, it was necessary, for normal subjects, to assume some sort of internediatc-term memory component which summed with the short-term memory component to produce the total memory trace.

If strength thcory is correct, then it should not be necessary to assume an intermediateterm component of the memory trace in either case for H.M., and H.M.'s data for both numbers and tones should be well fit by a single exponentially decaying short-term memory trace with approximately the same acquisition and decay parameters as normal subjects. On the other hand, if the good fit of strength theory for normal subjects was due to a fortuitous interaction of short-term and intermediate-term or long-term memory in a manner quite different from that postulated by strength theory, we might expect a subject without intermediate-term or long-term memory to show marked deviation from the single exponentially decaying trace postulated by strength theory for short-term menory.

At the same time, if H.M.'s data show close agreement with the short-term memory component of strength theory with acquisition and decay parameters within the range for normal subjects, and if his data do not require an intermediate-term or long-term component, then the present study will provide further support for the hypothesis that H.M. has a completely normal short-term memory accompanied by an inability to form new long-term memory traces.

\section{METHOD}

All the experiments reported in the present paper use the method of "yes-no" recognition memory for single items. The items in different experiments are single-digit numbers, three-digit numbers, or pure tones, and the retention intervals vary from $0.25 \mathrm{sec}$ to $8 \mathrm{sec}$. The general procedure is to present the item or list of items to be remembered and then after a delay to present a single test item about which H.M. must decide "yes" or "no" ("same" or "diffcrent") as to whether the test item had been presented previously on that trial.

\section{Exp. 1: Single digits}

Procedure. On each trial H.M. got a ready signal, followed in about $1 \mathrm{sec}$ by auditory presentation of a list of 8 single-digit numbers presented at a rate of 3 digits per sec, followed immediately by a single test digit, followed by H.M.'s decision as to whether the test (last) digit had occurred in the previous list of 8 digits. H.M. usually gave his answer within $2 \mathrm{sec}$ after the test letter and the next trial began about $3 \mathrm{sec}$ after this. In all the experiments 
reported in this paper, the trials themselves were rccorded on tape, but the experimenter started and stopped the tape recorder between trials to record H.M.'s responses.

H.M. had a card in front of him throughout the experiment which reminded him of the decision he was to make. The instruction on the card was as follows: "Did the last number appear earlier in the list?" From time to time the experimenter repeated this instruction aloud to H.M. and indicated that he should keep looking at the card to remind. himself of the task. We must keep in mind that on part or all of some trials H.M. may not have remembered what he was supposed to be doing, but as far as one can tell from his speed and alertness in performing the task, this was not a major problem.

Design. There were 11 different conditions in the experiment. In 9 of the conditions no digit was repeated in the list of 8 digits and the test digit was identical to the digit in the first, second, third,..., eighth position in the list or else was not identical to any digit in the list. The last condition occurred 3 times as often as the other conditions. In the other two conditions, the second and fifth digits in the list were identical and the test item was either that digit or a digit that did not occur in the list at all. Conditions were presented in random order in blocks of 13 trials. There were 21 different examples of each condition, some of which were presented twice and some three times to make a total of about 47 trials in each condition, except the false recognition condition after lists with no repeated itcms, which had about 141 trials. The $\mathrm{N}$ for each condition is actually slightly smaller than this because about 2 per cent of the trials were discarded due to failure of H.M. to respond.

\section{Exp. 2: Three-digit numbers}

Procedure. On each trial H.M. got a ready signal followed by a list of 3-digit numbers which was presented at the rate of one 3-digit number per sec, followed immediately by a test 3-digit number, followed by H.M.'s decision as to whether the test (last) 3-digit number had occurred earlier in the list. As in the previous experiment the subject had a card in front of him that reminded him of the instructions as follows: "Did the last 3-digit number appear earlier in the list?"

Design. Lists of five and seven 3-digit numbers were presented (in different sessions) and every serial position of each list length was tested approximately equally often ( $N$ of about 40 for each position in length- 5 lists and $N$ of about 50 for each position in length-7 lists). New 3-digit numbers (not present in the preceding list) were tested 99 times for length-5 lists and 186 times for length-7 lists. The same lists were used as in WICKELGREN and NORMAN [15], and that article should be consulted for details of list construction and randomization of conditions.

\section{Exp. 3: Pure tones}

Procedure. On each trial H.M. got a ready signal followed by a standard (S) tone lasting $2 \mathrm{sec}$, followed by an interference (I) tone lasting a variable $t_{I} s e c$, followed by a comparison (C) tone lasting $1 \mathrm{sec}$, followed by H.M.'s decision as to whether the $\mathrm{S}$ and $\mathrm{C}$ tones were the same or different in pitch. H.M. always had a card in front of him that said, "Did the first tone and the last tone sound the same or different in pitch?"

Design. There were 7 values of $t_{1}, 0.25,0.5,0.75,1,2,4$, and $8 \mathrm{sec}$, and 3 values of frequency difference between the $S$ and $C$ tones, $-10 \mathrm{cps}, 0 \mathrm{cps}$ (appeared twice as often 
as the others), and $10 \mathrm{cps}$. The $\mathrm{S}$ tones were randomly assigned frequencies between 400 and $490 \mathrm{cps}$ in $10 \mathrm{cps}$ steps. The I tone was $930 \mathrm{cps}$. Conditions were randomized in blocks of $7 \times 4=28$ trials, with 18 different blocks. Each block was tested about twice giving an $\mathrm{N}$ of about 72 for $0 \mathrm{cps}$ conditions and 36 each for 10 and $-10 \mathrm{cps}$ conditions.

\section{Response probabilities}

\section{RESULTS}

The probabilities of correct and false recognition for items from each serial position (k) in lists of 8 single-digit numbers and lists of 5 and 7 threc-digit numbers are shown in Table 1. Conditions where the test item was not in the prior list are indicated by a*.

Table 1. Correct and false recognition probabilities in H.M.'s short-term recognition memory for verbal stimuli

\begin{tabular}{|c|c|c|c|c|c|}
\hline \multicolumn{2}{|c|}{ Exp. 1 (Single digits) } & \multicolumn{4}{|c|}{ Exp. 2 (Digit triples) } \\
\hline \multirow[b]{2}{*}{ k } & \multirow[b]{2}{*}{$P($ yes $)$} & \multicolumn{2}{|c|}{ L5 } & \multicolumn{2}{|c|}{ L7 } \\
\hline & & $\mathrm{k}$ & $P($ yes $)$ & k & $P$ (yes) \\
\hline$*$ & 0.14 & $*$ & 0.04 & $*$ & 0.12 \\
\hline 1 & 0.91 & 1 & 0.44 & 1 & 0.29 \\
\hline 2 & 0.87 & 2 & 0.63 & 2 & 0.21 \\
\hline 3 & 0.85 & 3 & 0.84 & 3 & 0.31 \\
\hline 4 & 0.85 & 4 & 0.88 & 4 & 0.50 \\
\hline 5 & 0.92 & 5 & 1.00 & 5 & 0.64 \\
\hline 6 & 0.94 & & & 6 & 0.83 \\
\hline 7 & 1.00 & & & 7 & 1.00 \\
\hline 8 & 1.00 & & & & \\
\hline$* 2+5$ & 0.09 & & & & \\
\hline $2+5$ & 1.00 & & & & \\
\hline
\end{tabular}

The correct and false recognition conditions in the lists of 8 single-digit numbers where the second and fifth items were identical are indicated by 2,5 and $* 2,5$, respectively. The results indicate a general decline in frequency of correct recognition of a test item as the number of items intervening between presentation and test increases, but there appears to be some primacy effect as well, in the single-digit lists and the length-7, threedigit number lists.

The probabilities of correct and false recognition of comparison tones in the delayed comparison task are shown in Table 2 . Since only one item, the $S$ tone, is to be remembered and the different delay intervals $t_{l}$, could and undoubtedly did produce different biases to respond "same", it is necessary to assess both correct and false recognition rates for each $t_{1}$. On the whole, Table 2 indicates a deterioration in the accuracy of distinguishing 
$\mathrm{C}$ tones that are the same as or different from the $\mathrm{S}$ tone, with increasing (filled) delay between the two.

Table 2. Correct and false recognition probabilities in H.M.'s short-term recognition memory for pitch

\begin{tabular}{ccc}
\hline & $\frac{\text { Exp. 3 (Tones) }}{2}$ & \\
\cline { 2 - 3 } $\mathbf{t}_{\mathrm{f}}$ & 0.69 & $\mathrm{P}$ (Same $\mid \mathrm{S}-\mathrm{C}= \pm 10)$ \\
\hline 0.25 & 0.72 & 0.15 \\
0.50 & 0.78 & 0.17 \\
0.75 & 0.85 & 0.19 \\
1.0 & 0.88 & 0.32 \\
2.0 & 0.60 & 0.39 \\
4.0 & 0.32 & 0.44 \\
8.0 & & 0.31 \\
\hline
\end{tabular}

\section{Strength theory}

The correct and false recognition probabilities shown in Tables 1 and 2 can be transformed into measures of the difference between correct and false recognition conditions in average strength of the memory trace for the test items. This transformation from pairs of response probabilities into average strength-difference measures uses the criterion rule of signal detection theory, which can be applied in a very direct and plausible manner to recognition memory $[1,7,15]$. The essence of the theory is that correct and incorrect test items can be characterized by a unidimensional measure of strength in memory, the value of which, under constant experimental conditions, is approximately normally distributed with a mean which is higher for correct than for incorrect test items.

In general, it is not necessary to assume that the trace strength distributions have equal variance, but for the types of tasks reported in this paper, variances have always been approximately equal. It was not possible to obtain confidence judgments from H.M. in the present experiments. Thus, it was not possible to test the equal variance assumption for H.M., and we must assume that the variances of correct and incorrect strength distributions are approximately equal for H.M., just as they are for normal subjects. For the same reason, we must assume without direct proof that the strength distributions for H.M. are approximately normal, just as they are for normal subjects. Under these assumptions, one can obtain measures of the difference in mean strength for correct test items vs. incorrect test items. This strength difference is the $\mathrm{d}^{\prime}$ value obtained by looking up the correct and false recognition probabilities in the tables of $d^{\prime}$ of Elliotr [2]. So much for the decision assumptions of strength theory.

The short-term memory acquisition-assumption is essentially that presentation of an item boosts its mean strength by a certain amount and boosts the mean strength of an equivalence class of similar items by a lesser amount. Let the difference between these two initial acquisition strengths be $\alpha$ (where the unit of measurement is the standard deviation 
of the trace strength distributions). The acquisition parameter $(\alpha)$ represents the initial discriminability of correct vs. one class of incorrect test items, at the time of presenting the correct item.

The short-term memory decay assumption is that this difference in strength (discriminability) of the correct and incorrect test items decays exponentially as a function of the time delay interpolated between presentation and test, provided the time delay is filled with intervening activity to provent active rehearsal.

The prediction of strength theory for H.M.'s data is that the discriminability of correct vs. incorrect test items $\left(\mathrm{d}^{\prime}\right)$, in any task, will decay exponentially as a function of delay $\left(\mathrm{t}_{\mathrm{I}}\right)$. Thus, $\mathrm{d}^{\prime}\left(\mathrm{t}_{\mathrm{l}}\right)=\alpha \mathrm{e}_{\mathrm{J}}^{-\beta \mathrm{t}}$, where the decay rate $(\beta)$ would be expected to remain constant over different tasks, but the acquisition constant $(\alpha)$ might vary considerably depending on the similarity of the correct vs. incorrect test items. For example, if one used incorrect $\mathrm{C}$ tones $20 \mathrm{cps}$ from the $\mathrm{S}$ tone, one would certainly expect to find a larger value of the acquisition parameter $(\alpha)$, but one would not expect the decay rate $(\beta)$ to change.

\section{Goodness-of-fit of strength theory}

According to the strength theory just described, $\log \left[\mathrm{d}^{\prime}\left(\mathrm{t}_{\mathrm{I}}\right)\right]$ is a linear function of $\mathrm{t}_{1}$ with a $y$-intercept of $\alpha$ and a slope of $-\beta$. The results of such semi-logarithmic plots of the empirically obtained $d^{\prime}\left(t_{\mathrm{I}}\right)$ values for single digits, length-5 digit triples, length-7 digit triples, and pure tones are shown in Fig. 1.

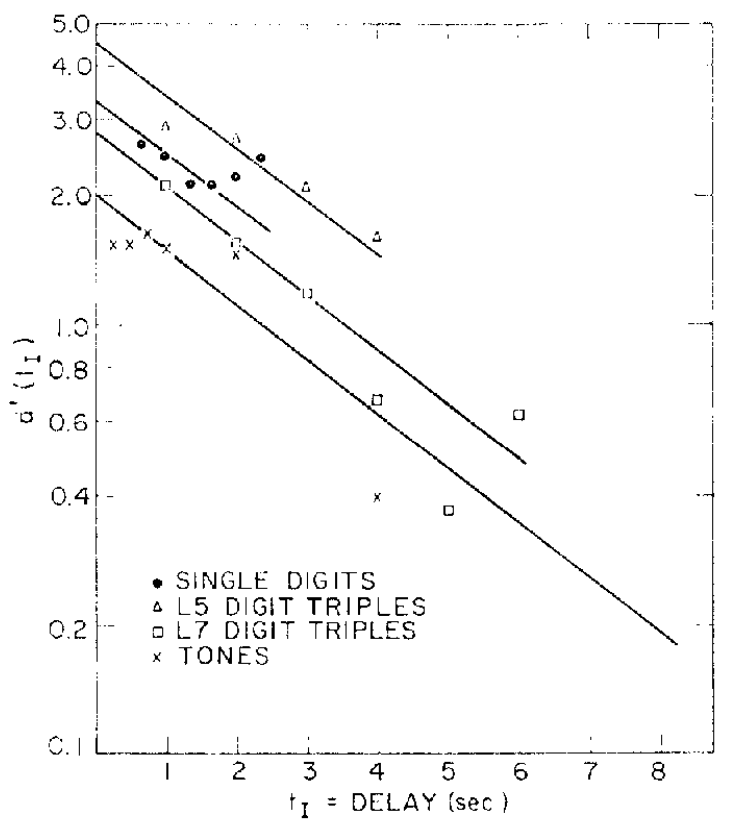

FIG, 1.

In all four cases, $\mathrm{d}^{\prime}$ has a marked tendency to decline with increasing delay. Furthermore, the rate of decay $(\beta)$ seems to be approximately the same in all four cases. However, the acquisition parameter $(\alpha)$ is different in each case. The theoretical lines shown in Fig. 1 are for $\beta=0.29$ and $\alpha=3.3,4.5,2.8$, and 2.0 for single digits, length-5 digit triples, length-7 triples, and pure tones, respectively. 
There are some interesting deviations from the theoretical lines shown in Fig. 1, namely, a marked primacy effect for single digits, a slight primacy effect for length-7 digit triples, and a peculiar flat portion of the decay curve for pitch in the region of $t_{I}$ less than $2 \mathrm{sec}$.

If one estimates $\alpha$ and $\beta$ for length-7 digit triples and uses the false recognition rate to estimate the criterion for a "yes" response, one can test the goodness-of-fit of the strength theory (in predicting the correct recognition rate) by a chi square test on $7-2=5$ d.f. For the length- 7 digit triples, $\chi^{2}=5.93$ on 5 d.f., $p>0.30$, indicating an extremely good fit of the theory to the data.

Now let us take the value of the short-term memory decay parameter $(\beta)$ estimated from the data for length-7 digit-triples and use it along with separate estimates of the acquisition and criterion parameters obtained from each other set of data, to obtain predictions of the correct recognition rates for each of the conditions of the other experiments. The chi square values for the fit of the theory to each of the other experiments were: $\chi^{2}=$ 11.65 on 7 d.f., $p>0.10$, for single digits, $\chi^{2}=6.56$ on 4 d.f., $p>0.10$ for length- 5 digit triples, and $\chi^{2}=12.15$ on 6 d.f., $p>0.05$ for pure tones. The goodness-of-fit tests indicate a reasonably good fit in every case.

The acquisition parameters for H.M. are somewhat lower than those obtained in the previous experiments using normal M.I.T. and Harvard students. This is hardly surprising, and of no theoretical significance, especially since his immediate memory span was somewhat below the memory span for normal M.I.T. and Harvard students, before his operation, and was not changed by the operation. The acquisition parameter is subject to differences in coding strategy, ability to maintain concentration, and the degree to which the subject follows instructions. Any or all of these factors, though particularly the last one, might account for H.M.'s slightly lower degree of original learning of each item. In any event, the nature of the memory trace is indicated not by the acquisition parameter, but by the form of the decay function and its decay rate parameter(s). H.M.'s decay functions appear to be reasonably well fit by a single exponentially decaying trace, with a decay rate completely within the range of decay rates for the short-term memory traces of normal subjects $[15,14]$.

The short-term memory component of strength theory provides a reasonably good description of the performance of a subject who has virtually no ability to form long-term memory traces. Thus, it cannot be argued that the good fit of strength theory for short-term memory in normal subjects is due to a complex interaction of short-term and long-term memory because a good fit is obtained for a subject who presumably has only short-term memory.

Certainly, no evidence was found in the present study to indicate the necessity of estimating any intermediate-term or long-term memory traces to fit the data of H.M. in any of the present experiments. This is particularly interesting since it has proved necessary to estimate an intermediate-term memory component to fit the pitch memory data in normal subjects (WICKELGREN $[13,14]$ ).

The primacy effects observed in two of three cases for H.M. are not surprising, since primacy effects in short-term memory have also been observed for normal subjects [15].

More disturbing is the flat portion of the decay curve for pitch memory in the region from 0.25 to $2 \mathrm{sec}$ for H.M. This could be due to rehearsal by H.M. during the interference tone, especially since it was impossible to instruct H.M. not to rehearse the standard tone during the interference tone. However, an attempt to get similar results from one normal subject who was instructed to rehearse the standard tone during the interference tone 
failed to show a comparably flat decay curve in the region of 0.25 to $2 \mathrm{sec}$, though there was a definite tendency in this direction. Perhaps H.M. is much more skilled at rehearsing in the presence of distraction. This interpretation of the flat portion in H.M.'s decay curve for tones must be considered completely tentative.

Probably the most disturbing feature of H.M.'s data is the vastly different degree of learning, $\alpha$, for each triple in length-5 as opposed to length-7 lists. No such difference was observed with normal subjects [15]. One expects differences in degree of learning for different types of items, but one does not, in general, expect differences for different list lengths.

The most plausible explanation, in my opinion, is that H.M. had a greater tendency to forget what he was supposed to be doing in the length-7 experiment than in the length-5 experiment. During acquisition, this could lead to a lower average degree of learning (boosting of strength) for presented items. During retrieval, this could lead to an increase in retrieval noise. Hence there would be a decrease in $d^{\prime}\left(t_{I}\right)$ for either or both of two reasons. First, the mean strength of old items is reduced, and/or second, the standard deviation of the retrieval noise (which is the unit of measurement of strength) is increased.

The latter effect would be reflected entirely in a reduced value of the acquisition parameter $(\alpha)$ with no effect on the decay parameter $(\beta)$ or the exponential shape of the decay function. The former effect is more difficult to analyze, requiring us to assume that acquisition $(\alpha)$ is a random variable, rather than a real variable. Any of the more plausible theories of the probabilistic aspects of H.M.'s acquisition will predict a reduction in the acquisition parameter. Unfortunately, they will also predict changes in the shape of the decay function, depending on the amount of acquisition noise. This being the case, the data suggest that the largest difference between length-5 and length-7 lists was an increase in retrieval noise, with the level of acquisition noise being rather small in cither case.

\section{DISCUSSION}

The overall fit of strength theory to H.M.'s data is quite satisfactory. That this good fit was achieved using the same decay rate in all four cases is particularly convincing. Nevertheless, there were some deviations from the theory that might have proven systematic in a larger experiment. Thus, the support of strength theory in the present study must be considered tentative.

However, what is overwhelmingly supported by the present study, in agreement with all previous studies of H.M. and subjects with similar deficits [5], is that there are at least two different memory traces in normal subjects, a short-term trace and a long-term trace. In view of the fact that H.M.'s short-term memory seems to be normal, while his ability to form new long-term memory traces is virtually completely absent, it seems rather unlikely that short-term and long-term memory are based on a single trace with different degrees of acquisition.

Of course, all that is definitely shown is that H.M. is lacking some vital component in the consolidation process for long-term memory traces. It is logically possible that this consolidation process simply boosts to a higher level the same trace established by external stimulation, and that no amount of external stimulation can boost the trace to this high level without the operation of the internal consolidation system. H.M.'s deficit is most simply explained by assuming that a different trace is established by the consolidation system. Nevertheless, it is possible to imagine a rather complex system in which the level of a single trace is a complicated function of external stimulation up to some level and of 
the internal consolidation process beyond that level. However, a variable-acquisition singletrace theory is contradicted by the vast difference in rate of decay observed in normal subjects for traces with the same strength, but established in short-term vs. long-term memory experiments.

MeLton [4] has suggested that we view memory as consisting of a single trace, whose rate of decay is a variable that is a function of the number of repetitions, the nature of the material being learned, the nature of the prior and subsequent material, etc. This variabledecay single-trace theory is much harder to distinguish from a dual-trace theory than is a variable-acquisition single-trace theory. However, H.M.'s data force the variable-decay theory to assume that the reduction in decay rate with multiple presentation depends on the operation of an internal consolidation process, while the initial establishment of the rapidly decaying trace depends on a different internal consolidation process. Thus, either type of single trace theory is required by H.M.'s data to postulate a dual consolidation process.

But what of the evidence that short-term memory has functional properties very similar to long-term memory $[3,4,6,8-11,13,16]$. The results of all of these studies can be summarized as indicating that short-term memory is associative, just as is long-term memory.* In verbal short-term memory at rapid rates of presentation, structural phonemic coding is much more important than any coding by meaning, whereas when subjects have more time to study the material to be remembered, they recode the material in a variety of other ways. Nevertheless, the storage is by the strengthening of associations between internal representatives in either case, only the nature of the internal representatives is different. Furthermore, although there is greater replication in different subsystems of the nervous system of the long-term traces than of the short-term traces, it is quite likely that all subsystems can have both short-term and long-term memory traces formed between their internal representatives.

Thus, all the evidence on the relationship between short-term and long-term memory can be summarized in the following manner. Short-term memory is mediated by a rapidly decaying facilitation of the association between (or within) internal representatives; longtern memory is mediated by a much more slowly decaying facilitation of the association between (or within) internal representatives. There are simply two different traces that can facilitate the same connections between internal representatives.

* When one is studying item recognition memory, as in the experiments reported in the present paper, one conceives of the facilitated associations to be those between the component parts of the internal representative of an item.

\section{REFERENCES}

1. EGAN, J. P. Recognition memory and the operating characteristic. Indiana University Hearing and Communication Laboratory. AFCRC-TN-58-51, AD-152650, 1958.

2. El.hotT, P. B. Table of $d^{\prime}$. In Signal Detection and Recognition by Human Observers, J. A. Swets (Editor), pp. 651-684. Wiley, New York, 1964.

3. Keppel, G. and Underwood, B. J. Proactive inhibition in short-term retention of single items. J. verb Learn. verb Behav. 1, 153-161, 1962.

4. Metton, A. W. Implications of short-term memory for a general theory of memory. J. verb Learn. verb Behav. 2, 1-21, 1963.

5. Milner, Brenda. Amnesia following operation on the temporal lobes. In Amnesia, C.W.M. WhitTy and O. L. ZANGwILL (Editors), pp. 109-133. Butterworth, London, 1966.

6. Murdock, B. B. The retention of individual items. J. exp. Psychol. 62, 618-625, 1961.

7. NoRman, D. A. and WiCKelgren, W. A. Short-term recognition memory for single digits and pairs of digits. J. exp. Psychol. 70, 479-489, 1965. 
8. Wickelgren, W. A. Short-term memory for repeated and non-repeated items. Quart. J. exp. Psychot, 17, 14-25, 1965.

9. WickelgRen, W. A. Acoustic similarity and retroactive interference in short-term memory. J. verb Learn. verb Behav. 4, 53-61, 1965.

10. WiCKflgren, W. A. Short-term memory for phonemically similar lists. Amer. J. Psychol. 78, 567-574, 1965.

11. Wickelgren, W. A. Phonemic similarity and interference in short-term memory for single letters. J. exp. Psychol. 71, 396-404, 1966.

12. WICKELGREN, W. A. Consolidation and retroactive interference in short-term recognition memory for pitch. J. exp. Psychol. 72, 250-259, 1966.

13. WiCkelgren, W. A. Associative intrusions in short-term recall. J. exp. Psychol. 72, 853-858, 1966.

14. WICKELGREN, W. A. Associative strength theory of recognition memory for pitch. (In press).

15. WiCkelgren, W. A. and Norman, D. A. Strength models and serial position in short-term recognition memory. J. math. Psychol. 3, 316-347, 1966.

16. Wickens, D. D., Born, D. G. and Al.Len, C. K. Proactive inhibition and item similarity in short-term memory. J. verb Learn. verb Behav. 2, 440-445, 1963.

Résumé-Les possibilités de reconnaissance mnésique à court terme d'une part de nombres à un et à trois chiffres et d'autre part de la hauteur de tons purs, ont été etudiées chez un sujet (H.M.) présentant une amnésie antérograde quasi-absolue sans déficit apparent de la rétention immédiate. La raison première de cette étude était d'éprouver une théorie dynamique de la mémoire développée à partir d'observations faites chez le sujet normal, théorie impliquant l'existence de deux traces mnésiques de forces différentes (dual-trace strength theory). A partir de cette théorie sur la mémoire à court terme, on étudie une courbe exponentielle de dégradation des engrammes dans le cas de H.M., courbe comparable à celle que l'on trouve chez le sujet normal. Ces résultats complètent les observations déjà faites chez H.M., observations qui supportent la théorie de la mémoire formulée par WICKCLGREN et NORMAN [15]

Zusammenfassung-Eine Versuchsperson (H.M.) wurde geprüft, bei der nicht nur ein normales kurzfristiges Erinnerungsvermögen zu bestehen scheint, sondern zugleich eine fast völlige Unfähigkeit, längerwährende Gedächtnisspuren zu bilden. Die Versuche wurden anhand von einstelligen und dreistelligen Zahlen, sowie auch anhand von Tonhöhen gewisser Grundtöne durchgeführt. Hauptzweck dieser Untersuchungen war es, den kurzfristigen Teil cincr doppelspurigen Gedächtnistheorie (verschiedene Prozesse für kurz- und langfristige Erinnerungen) zu prüfen. Diese Theorie, die wir für normale Versuchspersonen entwickelt hatten, unterscheidet zwei verschiedene Prozesse, einen für kurzfristige, und cinen weiteren für Jangfristige Spurenbildungen, wobei berücksichtigt werden muss, dass die Stärke der jeweiligen Spurenbildung sich mit der Zeit verändert (double-trace strength theory).

Die Kurven, die den Abfall in der Stärke der Spuren darstellen, sind bei H.M. annähernd exponentiell, ganz wie es in đer Stärketheorie (strength theory) für kurzfristiges Erinnerungsvermögen postuliert ist. Überdies unterscheidet sich der Grad dicses Abfalles bei H.M. nicht wesentlich von dem bei normalen Versuchspersonen. Diese Ergebnisse stimmen mit früher an H.M. getroffenen Beobachtungen überein, die gleichfalls eine Doppelspurtheoric des Gedächtnisses nahelegten. Insbesondere aber unterstützen die vorliegenden Beobachtungen die Stärketheorie des Gedächtnisses, die [15] von WiCKELGREN und NORMAN aufgestellt wurde. 